\title{
Effect of Blade Torsion on Modeling Results for the Small Wind Research Turbine (SWRT)
}

Conference Paper NREL/CP-500-39000 January 2006

\section{Preprint}

D. Corbus

National Renewable Energy Laboratory

A.C. Hansen and J. Minnema

Windward Engineering LLC

To be presented at the 2006 ASME Wind Energy Symposium Reno, Nevada

January 8-10, 2006

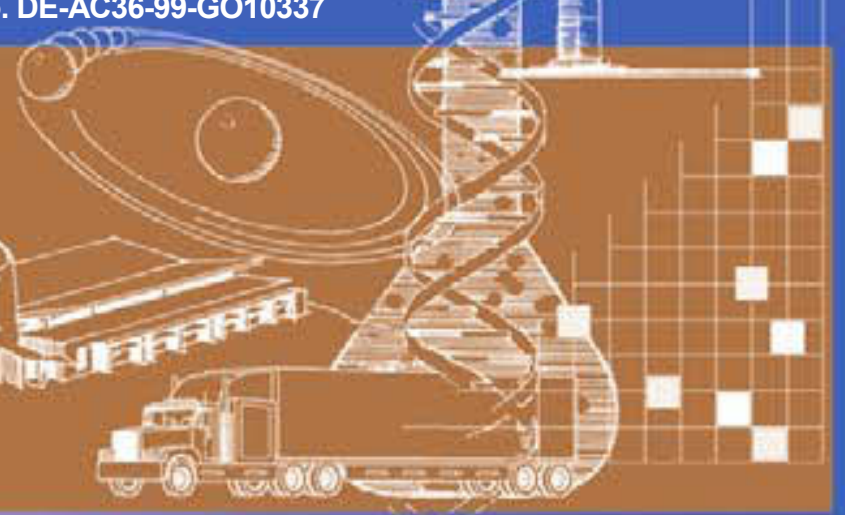




\section{NOTICE}

The submitted manuscript has been offered by an employee of the Midwest Research Institute (MRI), a contractor of the US Government under Contract No. DE-AC36-99G010337. Accordingly, the US Government and MRI retain a nonexclusive royalty-free license to publish or reproduce the published form of this contribution, or allow others to do so, for US Government purposes.

This report was prepared as an account of work sponsored by an agency of the United States government. Neither the United States government nor any agency thereof, nor any of their employees, makes any warranty, express or implied, or assumes any legal liability or responsibility for the accuracy, completeness, or usefulness of any information, apparatus, product, or process disclosed, or represents that its use would not infringe privately owned rights. Reference herein to any specific commercial product, process, or service by trade name, trademark, manufacturer, or otherwise does not necessarily constitute or imply its endorsement, recommendation, or favoring by the United States government or any agency thereof. The views and opinions of authors expressed herein do not necessarily state or reflect those of the United States government or any agency thereof.

Available electronically at http://www.osti.gov/bridge

Available for a processing fee to U.S. Department of Energy and its contractors, in paper, from:

U.S. Department of Energy

Office of Scientific and Technical Information

P.O. Box 62

Oak Ridge, TN 37831-0062

phone: 865.576.8401

fax: 865.576 .5728

email: mailto:reports@adonis.osti.gov

Available for sale to the public, in paper, from:

U.S. Department of Commerce

National Technical Information Service

5285 Port Royal Road

Springfield, VA 22161

phone: 800.553 .6847

fax: 703.605.6900

email: orders@ntis.fedworld.gov

online ordering: http://www.ntis.gov/ordering.htm 


\title{
Effect of Blade Torsion on Modeling Results for the Small Wind Research Turbine (SWRT)
}

\author{
Dave Corbus \\ National Wind Technology Center \\ National Renewable Energy Laboratory \\ 1617 Cole Boulevard \\ Golden, Colorado 80401-3393 (USA) \\ A. Craig Hansen, Jeff Minnema \\ Windward Engineering LLC \\ 2225 East Murray Holladay Road \#201A \\ Salt Lake City, Utah 84117 (USA)
}

\begin{abstract}
The Small Wind Research Turbine (SWRT) testing project was initiated with the goal of better characterizing both small wind turbine loads and dynamic behavior. The main purpose of the testing was to produce high quality data sets for model development and validation and to help the wind industry further their understanding of small wind turbine behavior, including furling. Previous papers have discussed modeling results for the SWRT using the FAST aeroelastic simulator. This paper summarizes modeling results from both the FAST and ADAMS aeroelastic simulators. The ADAMS model allows for blade torsional stiffness to be modeled, which is shown to significantly improve the agreement between model and test results for rotor speed and explain variances in previous comparisons between the SWRT FAST modeling results and the SWRT test data. The ADAMS model results also show that the aerodynamic pitching moment impacts the blade torsion more than the inertial forces.
\end{abstract}

\section{Introduction}

Small wind turbines provide unique challenges to researchers trying to model their performance because they Ohave higher RPMs than large wind turbines and often operate with large yaw errors and high yaw rates. Furthermore, many small wind turbines incorporate furling, whereby the rotor either tilts and/or yaws out of the wind to protect itself from overspeed during very high winds, and this can add further complications to modeling their performance. Because of these operating conditions, modeling the performance of small wind turbines is particularly challenging.

The Small Wind Research Turbine (SWRT) project was initiated with the goal of providing reliable data for a small furling wind turbine for model development, furthering the understanding of small wind turbine aerodynamics and furling, and model validation. The test was the most extensive loads test ever conducted for a small wind turbine ${ }^{1}$, and included measurements of turbine furling and thrust, as well as many other loads measurements.

The SWRT was modeled using the FAST ${ }^{2,3}$ (Fatigue, Aerodynamics, Structures, and Turbulence) code with the AeroDyn aerodynamic subroutine package developed by Windward Engineering LLC ${ }^{4}$ to calculate aerodynamic forces. FAST, which was developed and is distributed by the National Renewable Energy Laboratory's (NREL's) National Wind Technology Center (NWTC), is the primary aeroelastic simulator used by the U.S. wind industry to model small wind turbines. The recent upgrades to FAST allow users to simulate lateral offset and skew angle of the rotor shaft from the yaw axis, rotor-furling and tail-furling degrees-of-freedom (DOFs), up- and down-furl stops, and tail inertia and tail fin aerodynamic effects ${ }^{5}$. Because the location and orientation of the furling DOFs are userspecified, the simulator is flexible enough to model virtually any furling wind turbine configuration. FAST's builtin features allow for the determination of full-system modes, including furling, of an operating or stationary turbine. 
Extensive modeling of the SWRT turbine, using FAST, showed that rotor RPM was always over predicted, whereas the predicted and measured thrust were well correlated. This error in the rotor RPM was found for different airfoils and increased with wind speed ${ }^{6}$. Various approaches were tried to understand why the FAST model predicted rotor speeds much higher than measured in high winds. In low winds, the predictions were quite good. Both the airfoil tables and the alternator torque-speed curve were adjusted in various ways. Unrealistically large changes were required to improve the agreement in high winds, but then the accuracy in low winds was compromised. The reason for the discrepancy was finally discovered to be the elastic twist of the blade, which increases with rotor speed (or wind speed).

Subsequent modeling with ADAMS ${ }^{\circledR}$ (Automatic Dynamic Analysis of Mechanical Systems, "ADAMS" is used to imply "ADAMS ${ }^{\circledR \text { " }}$ throughout this paper) ${ }^{7}$, allowed blade torsion to be modeled. ADAMS is a general purpose, multibody-dynamics code from the MSC.Software Corporation for calculating multi-body dynamic forces that is adaptable for modeling wind turbines. FAST cannot currently model blade torsion.

The approach to modeling the SWRT consisted of the following: (1) upgrading the FAST model to include furling; (2) validating the FAST model by constructing an ADAMS model of the SWRT and comparing the two results for furling cases; (3) running simulations with the FAST model and comparing them to the SWRT test data; and finally, (4) including torsional blade stiffness in the ADAMs model and re-running the simulations performed in step (3) in ADAMs. This last step, which is the topic of this paper, was necessary because after lengthy data analysis and comparisons between FAST SWRT simulations and test data, it was determined that the "live twist" of the blade was having a significant impact on rotor performance. Torsional stiffness cannot currently be modeled in FAST, so the ADAMS model was used for the final simulations and the torsional stiffness of the blade was input into the model.

The ADAMS modeling with blade torsion as an input resulted in a significantly improved correlation between modeled and measured rotor RPM as discussed in this paper and revealed that blade torsion, referred to herein as "live twist", can have a very significant effect in wind turbine modeling.

\section{Test Turbine Description}

The SWRT is a modified Bergey EXCEL 10-kW turbine that furls horizontally out of the wind. The tail boom attaches with a hinge and bumper arrangement to the rotor/generator/main-frame assembly, and there is a lateral offset between the yaw axis and the rotor axis. The axis of the hinge pivot joint is inclined laterally at a small angle to the vertical yaw axis and produces a gravity restoring moment. A main-frame stop keeps the tail boom from furling more than about 68 degrees. As the wind speed increases, so do the thrust and aerodynamic normal force on the nominally aligned vertical tail at the end of the tail boom. Furling occurs when the rotor moments exceed the gravity restoring moment. The furl damper provides very little resistance to furling but a high resistance to unfurling 1 .

The Bergey EXCEL is a three-bladed upwind turbine with a rated output of $10 \mathrm{~kW}$ at $13.0 \mathrm{~m} / \mathrm{s}$. The EXCEL uses a permanent magnet alternator to produce three-phase variable frequency output at a nominal 240 -volts. The three-phase output is then rectified to DC power and converted to single-phase 240 -volt 60 -hz AC power by the Gridtek inverter. The turbine blades are constant chord and made from pultruded fiberglass, and the direction of rotation is counter-clockwise. The experimental data in this paper are from Configuration C of the SWRT, which has constant chord blades with the SH3055 airfoil, a swept area of $35.3 \mathrm{~m}^{2}$, and a rotor diameter of $6.7 \mathrm{~m}$. The turbine nacelle and shaft have an eight-degree tilt, and the SWRT is installed on a Rohn SSV, $24.4 \mathrm{~m}$. (80 ft.), freestanding lattice tower.

The SWRT was modified in several ways to allow for the installation of test instrumentation. One significant modification was the turbine main shaft was shortened approximately $0.18 \mathrm{~m}$. (7 in.) to allow for installation of a $0.18 \mathrm{~m}$ (7 in.) load fixture in-line with the non-rotating shaft to measure shaft loads. It should be noted that because the SWRT was modified, the test results in this report are not necessarily representative of the Bergey EXCEL turbine.

\section{Modeling Approach}

To supply inputs for aeroelastic models of the SWRT, the turbine tail assembly and mainframe were weighed and centers of gravity (Cgs) were determined. Tests were also conducted to calculate the inertia about the tail axis and the yaw axis. Tail damper properties were measured and all turbine geometries noted. A modal test was conducted for a blade to determine mode shapes for flap and edge. This data, as well as all turbine related parameters, including airfoil data, was input into the FAST and ADAMS models of the SWRT. To measure the blade torsion, $182.3 \mathrm{~N}-\mathrm{m}$ of torque was applied about the 0.25 chord of the blade. This was applied $2.74 \mathrm{~m}$ from the 
outboard edge of the rootpad (twisting $2.74 \mathrm{~m}$ of blade) and the measured angular deflection was 4.1 degrees or .022 degrees $/ \mathrm{N}-\mathrm{m}$ over $2.74 \mathrm{~m}$ of blade. Based on this data the torsional stiffness of the SH3055 blade is $6500 \mathrm{Nm}$. The c.g. offset is $0.017 \mathrm{~m}$ (towards the trailing edge) from the quarter chord.

The FAST and ADAMs models of the SWRT were developed using geometric, aerodynamic, and mass properties for the SWRT. The models include blade flexibility, a variable-speed generator with a torque-speed lookup table, tail furling with nonlinear user-defined springs and dampers, and free yaw.

Modeling data was compared to experimental data taken for the SWRT turbine ${ }^{1}$. Data were sampled at $160 \mathrm{hz}$, and a 40-hz, 6-pole low-pass Butterworth filter was used to filter the data. Records of 10 minutes in length were stored.

\section{SWRT Modeling}

\section{A. Blade Torsion}

Because the FAST program cannot model blade elastic torsion motion, an ADAMS model was created from the FAST model that includes the blade torsion degrees of freedom (DOF). The torsional stiffness of the blades was measured and input into the ADAMS model. The aerodynamic pitching moment was added to the airfoil tables so the ADAMS model includes both aerodynamic and inertial causes of blade twisting. There were no other changes to the model. Therefore, the only substantial reason for differences between the FAST and ADAMS predictions is live blade twist. (Previous work has shown that FAST and ADAMS predictions are nearly identical when blade torsion stiffness is very high ${ }^{5}$ ).

ADAMS and Fast predict blade motions differently. ADAMS uses 6 DOF per blade element, and there are 15 elements per blade for a total of 90 DOF per blade. Fast has 3 DOF per blade ( 2 flapwise and 1 edgewise) plus a polynomial mode shape for each DOF. ADAMS also requires blade torsional stiffness values, chordwise center of gravity $(\mathrm{Cg})$ offsets, and the option of using the center of mass $(\mathrm{Cm})$ values in the airfoil tables. Fast does not allow for any of these.

\section{B. Modeling Results for Summary Statistics}

Direct comparison of time series data is useful in that it provides a highly detailed view of a small amount of data. Comparisons of 10-minute average, maximum, and minimum summary statistics are valuable because they provide a view of a large quantity of data, albeit in much less detail. The statistics were compared by running the ADAMS model with simulated turbulent wind conditions generated by SNWind v1.22. An $8 \times 8$ grid of points was used across the rotor disc and three components of time-varying wind were generated at each grid point. The turbulence was generated with statistics that match the IEC Category-A conditions. Site-specific turbulent inputs were not used in this analysis. Figure 1 shows a plot of the actual turbulence intensity from the SWRT tests and the IEC Category A turbulence.

Figures 2-7 show the results of the summary statistics for SWRT Configuration C using the ADAMS model. These results were generated using the original 'untuned' airfoil and alternator data. They therefore represent the accuracy of predictions that would be done during a design if airfoil and alternator properties were available from wind tunnel or bench testing and blade elastic properties were known from Finite Element Analysis (FEA) or testing.

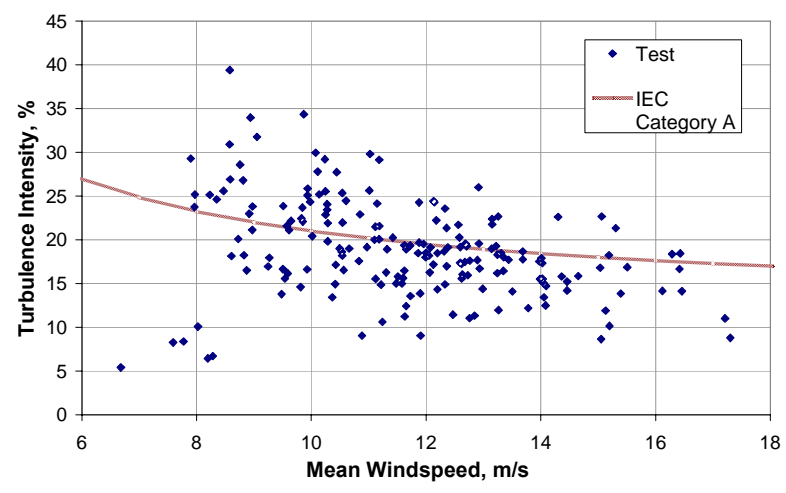

Figure 1. IEC Category A and test turbine turbulence intensities 


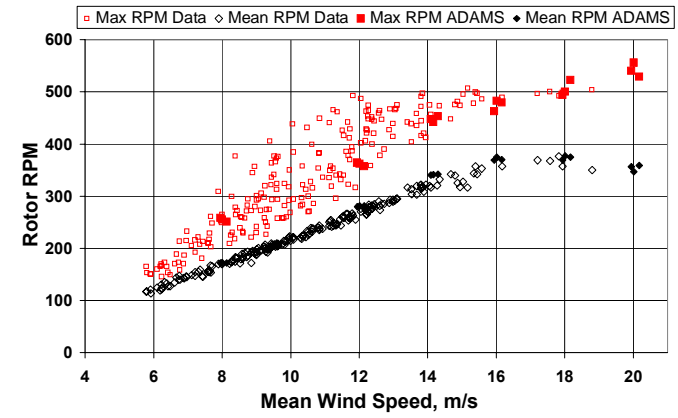

Figure 2. 10-Minute mean and maximum values of rotor RPM for Configuration $C$.

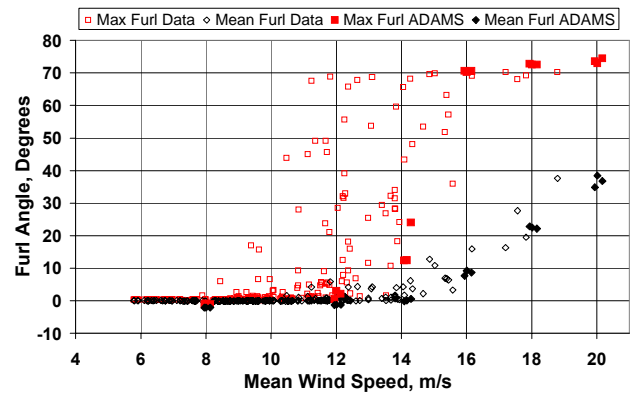

Figure 3. 10-Minute mean and maximum values of tail furl for Configuration $\mathrm{C}$.

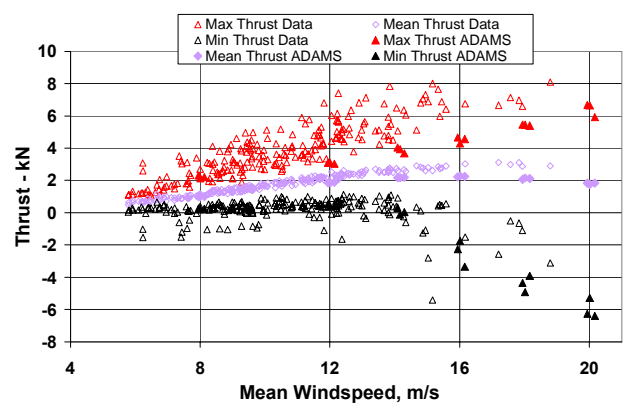

Figure 4. 10-Minute mean, minimum, and maximum values of thrust for Configuration $C$.

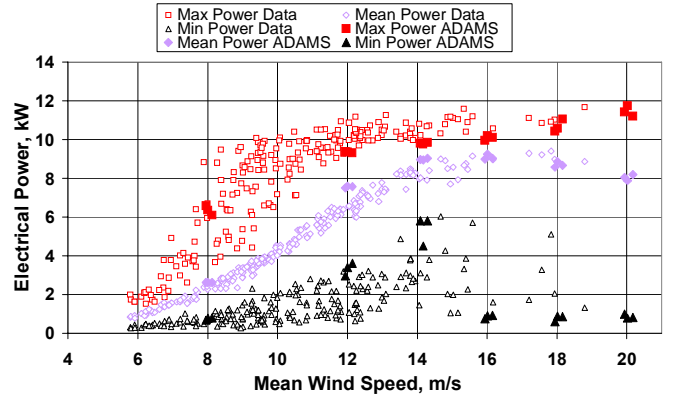

Figure 5. 10-Minute mean, maximum, and minimum values of electric power for Configuration C.

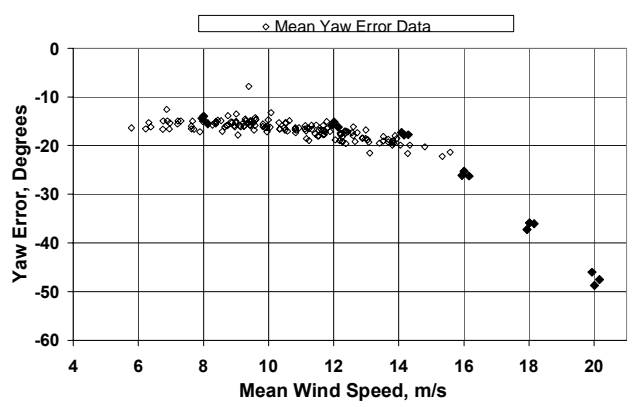

Figure 6. 10-Minute mean values of yaw error for Configuration $C$.

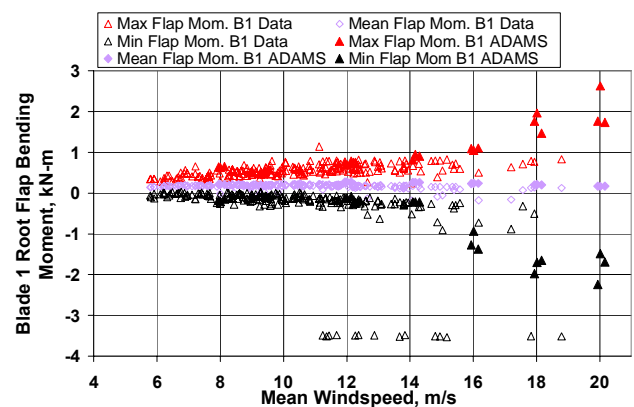

Figure 7. 10-Minute mean, maximum, and minimum values of Blade 1 flap bending for Configuration C. 


\section{Time Series Modeling Results}

Time series comparisons are made by driving the ADAMS model with measured wind data. Measurements of the hub-height horizontal and vertical wind speeds and the wind direction are used for the comparisons. Measurements of instantaneous horizontal wind shear were not available. Horizontal wind shear is known to be an important driver of yaw and furling motions ${ }^{8}$, but it is difficult to measure. Driving a model with "hub-height" wind data misses small-scale turbulence effects but captures the large-scale, slow variations in wind characteristics.

Figure 8 is a plot of blade elastic twist versus rotor RPM. The twist can be up to $4 \mathrm{deg}$. at higher RPMs. Figure 9 is a time series plot of blade elastic twist for the SWRT that shows the large amount of live twist during one 10minute time series file with an average wind speed of $16.2 \mathrm{~m} / \mathrm{s}$. Figures 10-13 show the same time series file for RPM, furl, thrust, and yaw error. The FAST modeling results without torsional stiffness are also shown in addition to the ADAMS results with torsional stiffness. The agreement between the ADAMS model data and test data is good, whereas the FAST model severely over predicts rotor RPM, and furl and yaw error agreement are also poor. The results demonstrate the importance of blade live twist to modeling, especially for the RPM.

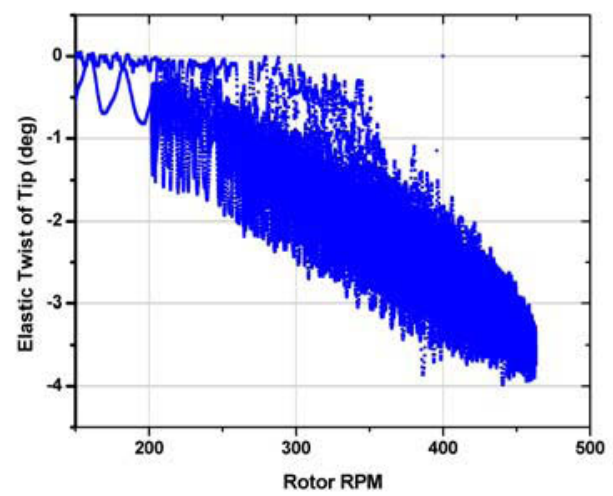

Figure 8. Elastic twist versus rotor RPM for one 10-minute test of Configuration $\mathrm{C}$.

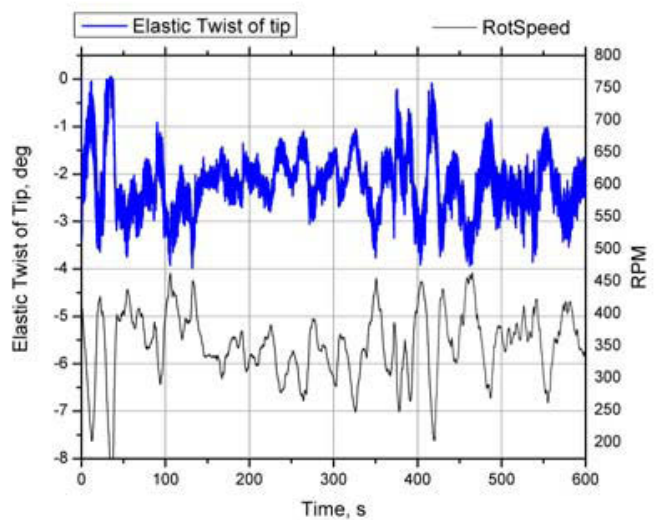

Figure 9. Elastic twist of blade tip and rotor RPM versus time for same 10-minute test (negative twist is toward feather).

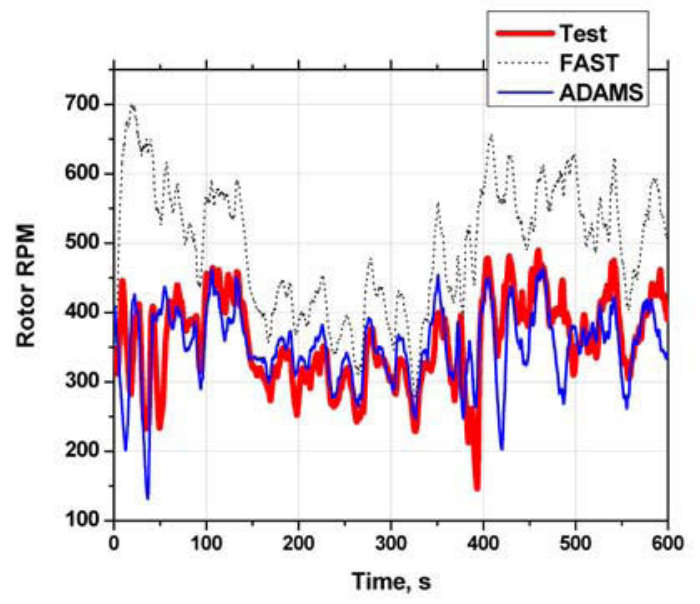

Figure 10. Rotor RPM versus time for same 10minute test.

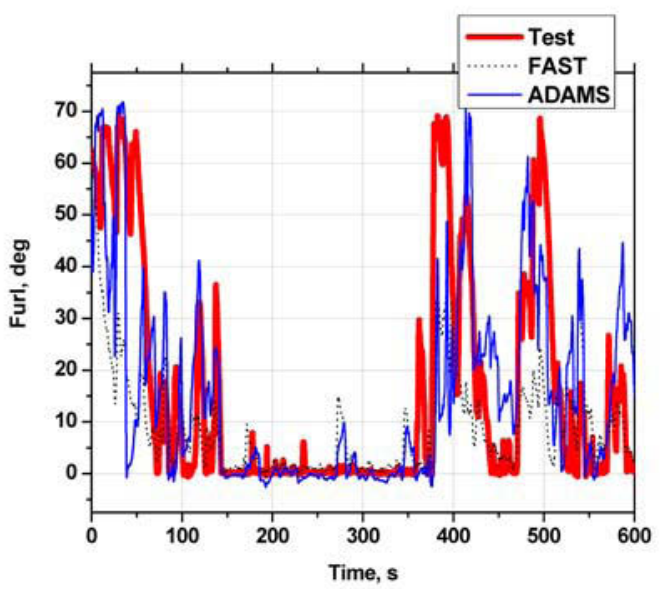

Figure 11. Rotor furl versus time for same 10minute test. 


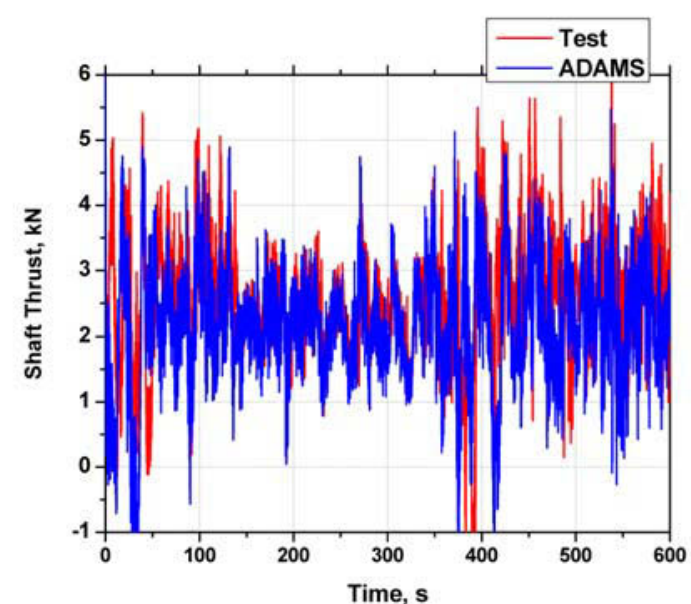

Figure 12. Rotor thrust versus time for same 10minute test.

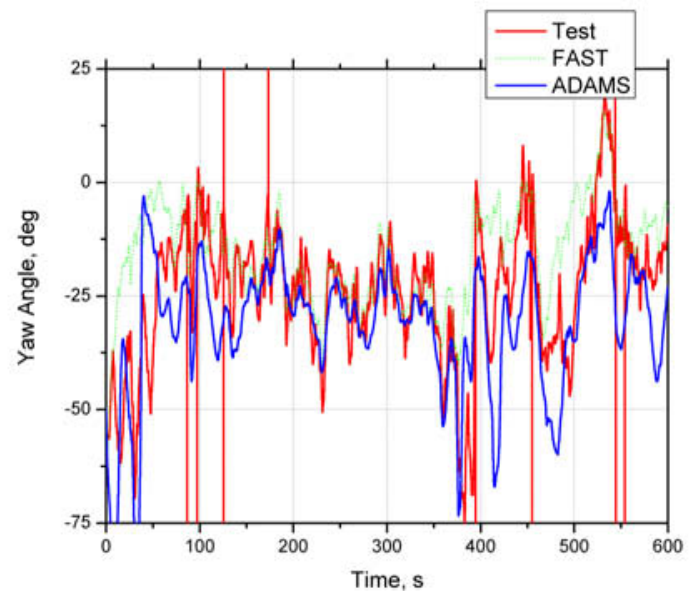

Figure 13. Yaw error versus time for same 10minute test.

\section{Effect of Aerodynamic Pitching Moment and Wake Model Algorithm on ADAMS Results}

Modeled sensitivity analyses with ADAMS show the importance of the aerodynamic pitching moment to the blade live twist. Figure 14 shows a plot of rotor speed versus time for the same 10-minute data series shown previously with the aerodynamic pitching moment turned both on (i.e. $\mathrm{Cm}$ ) and off (i.e. No $\mathrm{Cm}$ ). The data show aerodynamic forces have a large impact on "live" blade twist. Live blade twist has a big impact on RPM and hence power. Figure 15 shows a plot of electric power output versus time for the same 10-minute data set.

Figures 14 and 15 also show the effect of changing the dynamic inflow option in ADAMS. When the value is DYNIN $^{4}$, a generalized dynamic wake (GDW) inflow model is used to calculate the induction factor. A value of EQUIL ${ }^{4}$ assumes that the wake is always in equilibrium with the forces on a blade element (the "quasi-steady" or equilibrium wake assumption). For EQUIL, the BEM theory with skewed wake and tip loss corrections is used. The GDW model was developed as an expanded version of the Pitt and Peters model. It uses a series solution to describe the induced velocity field in the rotor plane, which includes Legendre functions in the radial direction and trigonometric functions in the tangential direction. The current GDW model in AeroDyn employs 0P, 1P, 2P and 3P terms ${ }^{4}$. The dynamic inflow effect is often insignificant, so results in most cases should not differ from the BEM results. The exception is cases with rapid changes in blade angle-of-attack, where the dynamic inflow effect can be significant, as is the case with the SWRT turbine. Yaw oscillation resulting from the GDW model has also been observed while modeling a small, upwind, tail-vane turbine, though the reasons for this are not yet known ${ }^{4}$.

\section{E. Comparison of Rotor RPM between ADAMS and SWRT Data}

Comparisons between predicted rotor RPM for the ADAMS model and measured rotor RPM from the SWRT data show some interesting trends depending on if the GDW or BEM wake model is used. Figure 16 shows summary statistics for rotor RPM versus wind speed for the ADAMS model results with the two different wake models and the SWRT data for Configuration C. The aerodynamic pitching moment is turned on in these ADAMS plots. 


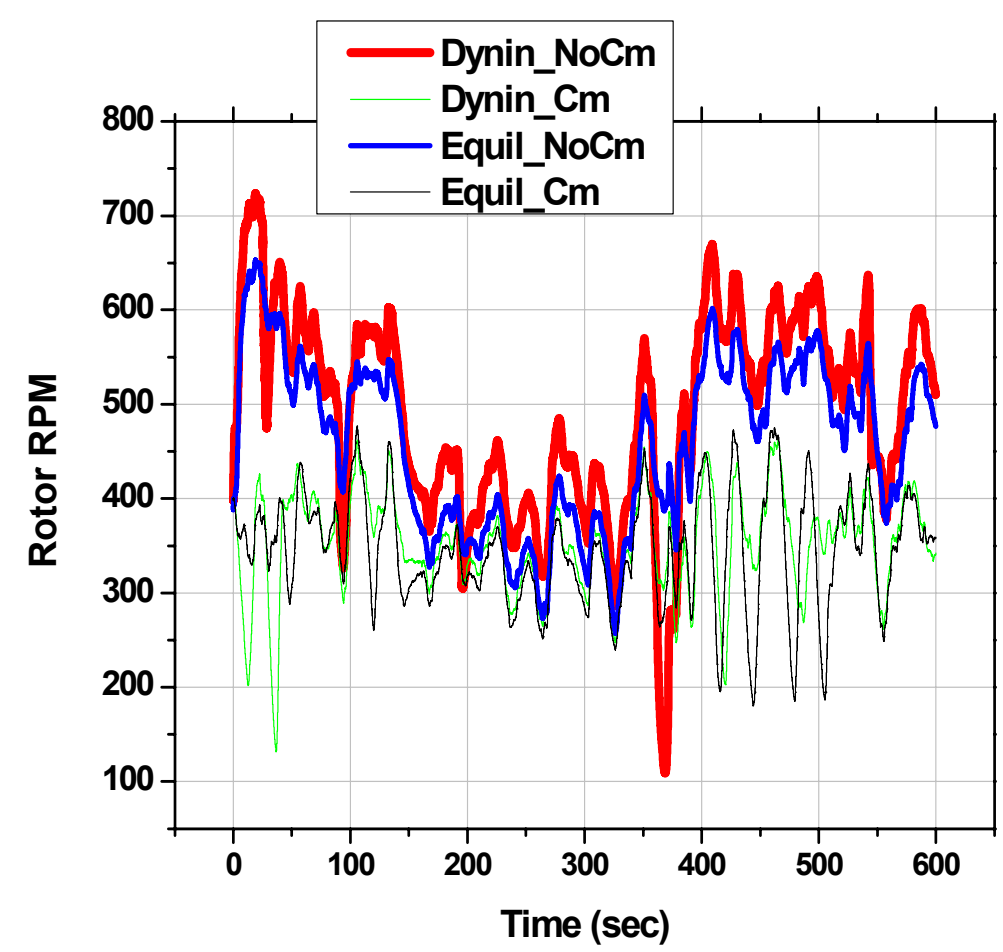

Figure 14. 10-Minute mean and maximum values of rotor RPM for Configuration $C$.

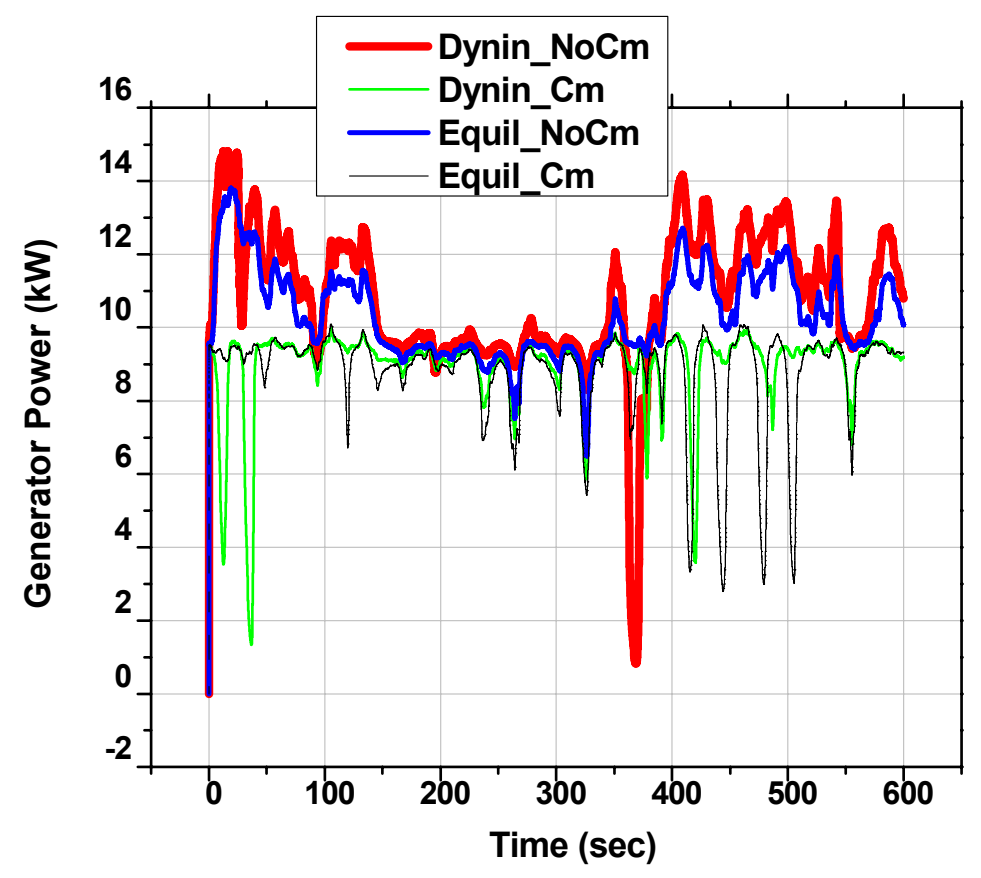

Figure 15. 10-Minute mean and maximum values of rotor RPM for Configuration $C$. 


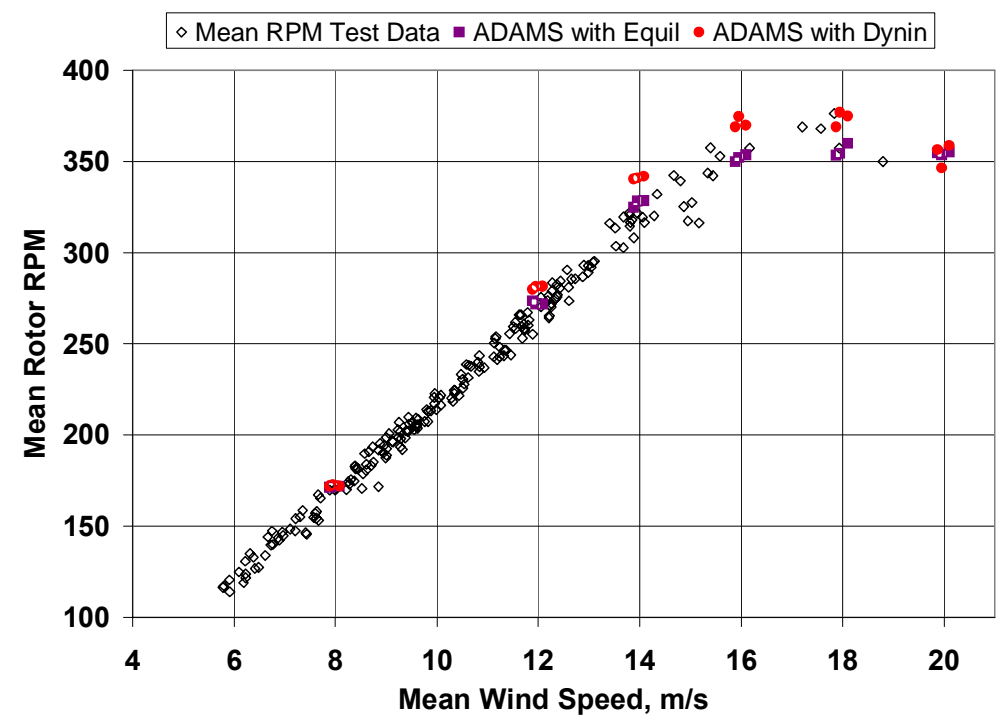

Figure 16. Rotor RPM versus wind speed for ADAMS with two different wake models and SWRT data.

\section{Conclusion}

The SWRT test has provided the small wind turbine and research community with a unique set of data for validating aerodynamic models for a turbine that operates at a significant yaw error, has high yaw rates, is in and out of stall quickly, and operates at higher RPMs. Analysis and comparison of FAST and ADAMS model simulations and test data for the SWRT has resulted in a better understanding of small wind turbine modeling, as well as a FAST furling model that can be used by engineers to better design small furling wind turbines. However, comparison of FAST and ADAMS results has shown the importance of including blade torsion in the SWRT model, which can only be done with the ADAMS model at this time. The SWRT blade is quite soft in torsion; hence it is doubtful that live twist will be as important for many other turbines. It was shown with the ADAMS model that the aerodynamic pitch moment has more of an effect on blade torsion than do inertial forces. Future near-term changes to the FAST model will include adding the ability to model blade torsion.

\section{Acknowledgments}

The authors would like to thank Mark Meadors of NREL for his technical help in conducting the SWRT testing, Jason Jonkman of NREL for his help in upgrading the FAST model to include the effects of furling, and Kathy O'Dell of NREL for her help in making this document more readable. We would also like to thank Todd Hanley of Bergey Windpower for his continuous help during both the testing and modeling phase of the project.

\section{References}

${ }^{1}$ Corbus, D. and Prascher, D. "Analysis and Comparison of Test Results from the Small Wind Research Turbine Test Project," Collection of the 2005 ASME Wind Energy Symposium Technical Papers Presented at the $43^{\text {rd }}$ AIAA Aerospace Sciences Meeting and Exhibit, 10-13 January 2005, Reno, NV., Washington, D.C.: American Institute of Aeronautics and Astronautics, January 2005, NREL/CP-500-36891. 
2 Jonkman, J.M. and Buhl, M.L. (March 2004). "FAST User's Guide”. NREL/EL-500-29798. Golden, CO: National Renewable Energy Laboratory, 105 pp.

${ }^{3}$ Jonkman, J.M. and Buhl, M.L. (January 2004). "New Developments for the NWTC's FAST Aeroelastic HAWT Simulator," Collection of the 2004 ASME Wind Energy Symposium Technical Papers Presented at the $42^{\text {rd }}$ AIAA Aerospace Sciences Meeting and Exhibit, 5-8 January 2004, Reno, NV. Washington, D.C.: American Institute of Aeronautics and Astronautics, pp. 181-191; NREL/CP-500-35077.

${ }^{4}$ David J. and Hansen, A. Craig. (September 2001). User's Guide to the Computer Software Routines AeroDyn Interface for $A D A M S^{\circledR}$. Salt Lake City, UT: Windward Engineering LLC, Prepared for the National Renewable Energy Laboratory under Subcontract No. TCX-9-29209-01, 24 pp.

5 Jonkman, J.M. and Hansen, A.C., "Development and Validation of an Aeroelastic Model of a Small Furling Wind Turbine," Collection of the 2005 ASME Wind Energy Symposium Technical Papers Presented at the $43^{\text {rd }}$ AIAA Aerospace Sciences Meeting and Exhibit, 10-13 January 2005, Reno, NV. Washington, D.C.: American Institute of Aeronautics and Astronautics, January 2005, NREL/CP-500-36776.

${ }^{6}$ Corbus, D. and Hansen, C. (2005). "Test Results from the Small Wind Research Turbine (SWRT) Test Project." Prepared for the WindPower 2005 Conference Proceedings, May 2005. NREL/CP-500-38224. Golden, CO: National Renewable Energy Laboratory, $14 \mathrm{pp}$.

${ }^{7}$ Laino, David J. and Hansen, A. Craig. (September 2001). User's Guide to the Computer Software Routines AeroDyn Interface for $A D A M S^{\circledR}$. Salt Lake City, UT: Windward Engineering LLC, Prepared for the National Renewable Energy Laboratory under Subcontract No. TCX-9-29209-01, 24 pp.

${ }^{8}$ Hansen, A.C. (May 1992). Yaw Dynamics of Horizontal Axis Wind Turbines, Final Report. NREL/TP-442-4822. Golden, CO: National Renewable Energy Laboratory. 


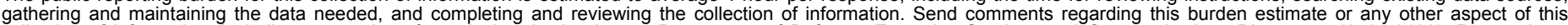

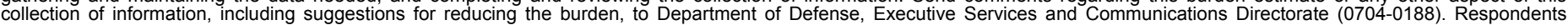

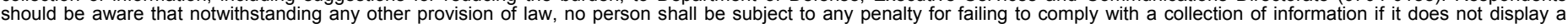

currently valid OMB control number.

PLEASE DO NOT RETURN YOUR FORM TO THE ABOVE ORGANIZATION.

\begin{tabular}{l|l|l|l} 
1. REPORT DATE $(D D-M M-Y Y Y Y)$ & 2. REPORT TYPE & 3. DATES COVERED (FrOm - TO)
\end{tabular} January 2006

Conference Paper

4. TITLE AND SUBTITLE

Effect of Blade Torsion on Modeling Results for the Small Wind

Research Turbine (SWRT): Preprint 5a. CONTRACT NUMBER

DE-AC36-99-G010337

5b. GRANT NUMBER

5c. PROGRAM ELEMENT NUMBER

5d. PROJECT NUMBER

NREL/CP-500-39000

5e. TASK NUMBER

WER6.3102

5f. WORK UNIT NUMBER
7. PERFORMING ORGANIZATION NAME(S) AND ADDRESS(ES)

National Renewable Energy Laboratory

1617 Cole Blvd.

Golden, CO 80401-3393
8. PERFORMING ORGANIZATION REPORT NUMBER

NREL/CP-500-39000

9. SPONSORING/MONITORING AGENCY NAME(S) AND ADDRESS(ES)

10. SPONSOR/MONITOR'S ACRONYM(S) NREL

11. SPONSORING/MONITORING AGENCY REPORT NUMBER

12. DISTRIBUTION AVAILABILITY STATEMENT

National Technical Information Service

U.S. Department of Commerce

5285 Port Royal Road

Springfield, VA 22161

13. SUPPLEMENTARY NOTES

14. ABSTRACT (Maximum 200 Words)

The Small Wind Research Turbine (SWRT) testing project was initiated with the goal of better characterizing both small wind turbine loads and dynamic behavior. The main purpose of the testing was to produce high quality data sets for model development and validation and to help the wind industry further their understanding of small wind turbine behavior, including furling. Previous papers have discussed modeling results for the SWRT using the FAST aeroelastic simulator. This paper summarizes modeling results from both the FAST and ADAMS aeroelastic simulators. The ADAMS model allows for blade torsional stiffness to be modeled, which is shown to significantly improve the agreement between model and test results for rotor speed and explain variances in previous comparisons between the SWRT FAST modeling results and the SWRT test data. The ADAMS model results also show that the aerodynamic pitching moment impacts the blade torsion more than the inertial forces.

15. SUBJECT TERMS

small wind research turbine; furling; FAST; ADAMS

\begin{tabular}{|c|c|c|c|c|}
\hline \multicolumn{3}{|c|}{ 16. SECURITY CLASSIFICATION OF: } & \multirow{2}{*}{$\begin{array}{l}\text { 17. LIMITATION } \\
\text { OF ABSTRACT } \\
\text { UL }\end{array}$} & \multirow{2}{*}{$\begin{array}{l}\text { 18. NUMBER } \\
\text { OF PAGES }\end{array}$} \\
\hline $\begin{array}{l}\text { a. REPORT } \\
\text { Unclassified }\end{array}$ & $\begin{array}{l}\text { b. ABSTRACT } \\
\text { Unclassified }\end{array}$ & $\begin{array}{l}\text { c. THIS PAGE } \\
\text { Unclassified }\end{array}$ & & \\
\hline
\end{tabular}

19a. NAME OF RESPONSIBLE PERSON

19b. TELEPHONE NUMBER (Include area code) 